\title{
Analysis of microsatellites in the vulnerable orchid Gastrodia flavilabella: the development of microsatellite markers, and cross-species amplification in Gastrodia
}

\author{
Chi-Chu Tsai ${ }^{1 \dagger}$, Pei-Yin $\mathrm{Wu}^{2+}$, Chia-Chi Kuo ${ }^{3}$, Min-Chun Huang ${ }^{4}$, Sheng-Kun Yu ${ }^{5}$ Tsai-Wen Hsu ${ }^{6 *}$,
} Tzen-Yuh Chiang ${ }^{2^{*}}$ and Yu-Chung Chiang ${ }^{4^{*}}$

\begin{abstract}
Background: Gastrodia flabilabella is a mycoheterotrophic orchid that obtains carbohydrates and nutrients from its symbiotic mycorrhizal fungi. The species is an endemic and vulnerable species enlisted in the "A Preliminary Red List of Taiwanese Vascular Plants" according to the IUCN Red List Categories and Criteria Version 3.1. G. flabilabella dwells the underground of broadleaf and coniferous forest with richness litter. Based on herbarium records, this species is distributed in central Taiwan. Twenty eight microsatellite loci were developed in G. flabilabella and were tested for cross-species amplification in additional taxa of G. confusoides, G. elata, and G. javanica. We estimated the genetic variation that is valuable for conservation management and the development of the molecular identification system for G. elata, a traditional Chinese medicine herb.

Results: Microsatellite primer sets were developed from G. flabilabella using the modified AFLP and magnetic bead enrichment method. In total, 257 microsatellite loci were obtained from a magnetic bead enrichment SSR library. Of the 28 microsatellite loci, 16 were polymorphic, in which the number of alleles ranged from 2 to 15 , with the observed heterozygosity ranging from 0.02 to 1.00 . In total, 15,13 , and 7 of the loci were found to be interspecifically amplifiable to G. confusoides, G. elata, and G. javanica, respectively.

Conclusions: Amplifiable and transferable microsatellite loci are potentially useful for future studies in investigating intraspecific genetic variation, reconstructing phylogeographic patterns among closely related species, and establishing the standard operating system of molecular identification in Gastrodia.
\end{abstract}

Keywords: Gastrodia; Conservation; Microsatellites; Mycoheterotrophic orchid; Population genetics; Simple sequence repeat markers

\section{Background}

Gastrodia is the largest achlorophyllous and mycoheterotrophic genus in the Orchidaceae with 50 to 60 species in the world. Recent studies recognized 19 species, including 13 endemic species distributed in Taiwan (Hsu 2008; Leou

\footnotetext{
* Correspondence: twhsu@tesri.gov.tw; tychiang@mail.ncku.edu.tw; yuchung@mail.nsysu.edu.tw

${ }^{\dagger}$ Equal contributors

${ }^{6}$ Endemic Species Research Institute, Nantou 552, Taiwan

2Department of Life Science, National Cheng Kung University, Tainan 701, Taiwan ${ }^{4}$ Department of Biological Sciences, National Sun Yat-sen University, Kaohsiung 804, Taiwan

Full list of author information is available at the end of the article
}

2000; Hsu and Kuo 2010; Chung and Hsu 2006). Species diversity in Taiwan Island is one of the hot spots of Gastrodia in the world. Gastrodia elata Blume is an important Chinese medicine that provides supplement to protect neuron and cardiovascular systems (Baek et al. 1999). Ecologically, Gastrodia species are saprophyte (Leou 2000), growing underground of forest or bamboo grove with richness litter and obtaining carbohydrates and nutrients from its symbiotic mycorrhizal fungi, including Armillaria mellea and other microbial species (Cha and Igarashi 1995). Due to such a unique growth form, Gastrodia species are difficult to find except the flowering 
and fruiting seasons, generally 2 to 4 weeks after budding. Most Gastrodia species are vulnerable to the human destruction. As a result, 7 species recognized as threatened species, including one as critically endangered, three as endangered, and another three as vulnerable, are evaluated by the IUCN Red List Categories and Criteria Version 3.1 (IUCN 2012) and listed in the "A Preliminary Red List of Taiwanese Vascular Plants" (Wang et al. 2012a).

Gastrodia flavilabella S.S. Ying is an endemic and vulnerable species with only few populations distributed at the edges of conifer plantation or natural broadleaf forests restricted to the central mountainous regions from 1,000 to 1,300 meters altitude (Leou 2000). This taxon is characterized by tuberous horizontal rhizomes ca. 4 to $10 \mathrm{~cm}$ in length and $0.6-1.6 \mathrm{~cm}$ in width bearing many coral-like buds (Leou 2000). Unique life form and habitat preference lead his species to be rare and vulnerable. However, no data for the genetic diversity in this species or genus are available, which is critical for evaluating the population dynamics and conservation genetics for conservation management.

Microsatellite genotyping is the most popular molecular tool for evaluating the structure and genetic diversity of populations because of its high genetic variability (cf. Ho et al. 2014). With co-dominant inheritance, the information of microsatellite genotyping can estimate the effective population sizes in ancestral and present populations (Ge et al. 2014), Hardy-Weinberg Equilibrium (Ge et al. 2012), and levels of introgression (Liao et al. 2012). In addition, microsatellite genotyping technology was extended to molecular identification system for paternity testing and cultivar identification (Tsai et al. 2013).

In this study, we constructed a microsatellite enriched library and developed microsatellite loci for future estimating the population genetic diversity based on microsatellite genotyping. The application of the microsatellite primers developed in this study was tested in other taxa of Gastrodia, specifically three taxa for polymorphism test and 13 species for transferability test.

\section{Methods}

\section{Sampling and DNA extractions}

Twenty individuals from each of four taxa in Gastrodia, including G. flavilabella from Nantou, G. elata from China, G. javanica (Blume) Lindl. from Lanyu Islet, and G. confusoides T. C. Hsu, S. W. Chung \& C. M. Kuo from Taichung (Table 1) were sampled for polymorphism test. One individual of G. flavilabella was used to construct a microsatellite enriched library and to develop microsatellite loci. To test the transferability of these newly designed microsatellite primers, two individuals of other 13 native taxa listed in Table 1 , specifically 8 endemic species, were sampled from the field. The sample location, sample size, and deposited herbarium for the voucher specimens are listed in Table 1. To avoid the contamination from the symbiotic mycorrhizal fungi, we collected the flower buds or seed pods for extracting total genomic DNA. Total DNA was

Table 1 Sample location for each species of the Gastrodia

\begin{tabular}{|c|c|c|c|c|c|c|}
\hline Species & Location & Species code & Sample size & Latitude & Longitude & Herbarium \\
\hline Gastrodia flavilabella & Nantou, Taiwan & Gfl & 20 & $\mathrm{~N} 23^{\circ} 39^{\prime} 43^{\prime \prime}$ & E $120^{\circ} 47^{\prime} 41^{\prime \prime}$ & TAIE \\
\hline Gastrodia elata & Yunan, China & Gel & 20 & $\mathrm{~N} 27^{\circ} 46^{\prime} 07^{\prime \prime}$ & E $104^{\circ} 15^{\prime} 39^{\prime \prime}$ & TAIE \\
\hline Gastrodia javanica & Lanyu, Taiwan & Gja & 20 & N $22^{\circ} 00^{\prime} 53^{\prime \prime}$ & E $121^{\circ} 34^{\prime} 17^{\prime \prime}$ & TAIE \\
\hline Gastrodia confusoides & Taichung, Taiwan & GCO & 20 & $\mathrm{~N} 24^{\circ} 14^{\prime} 21^{\prime \prime}$ & E $120^{\circ} 54^{\prime} 81^{\prime \prime}$ & TAIE \\
\hline Gastrodia albida & Taipei, Taiwan & Gal & 2 & $\mathrm{~N} 24^{\circ} 50^{\prime} 36^{\prime \prime}$ & E $121^{\circ} 33^{\prime} 28^{\prime \prime}$ & TAIE \\
\hline Gastrodia appendiculata & Nantou, Taiwan & Gap & 2 & $\mathrm{~N} 23^{\circ} 41^{\prime} 17^{\prime \prime}$ & E $120^{\circ} 47^{\prime} 26^{\prime \prime}$ & TAIE \\
\hline Gastrodia autumnalis & Taoyuan, Taiwan & Gau & 2 & $\mathrm{~N} 24^{\circ} 47^{\prime} 34^{\prime \prime}$ & E $121^{\circ} 26^{\prime} 08^{\prime \prime}$ & TAIE \\
\hline Gastrodia clausa & Taipei, Taiwan & $\mathrm{GCl}$ & 2 & $N 25^{\circ} 04^{\prime} 57^{\prime \prime}$ & E $121^{\circ} 37^{\prime} 33^{\prime \prime}$ & TAIE \\
\hline Gastrodia fontinalis & Taipei, Taiwan & Gfo & 2 & $\mathrm{~N} 24^{\circ} 51^{\prime} 27^{\prime \prime}$ & E $121^{\circ} 32^{\prime} 19^{\prime \prime}$ & TAIE \\
\hline Gastrodia gracilis & Chaiyi, Taiwan & Ggr & 2 & N $23^{\circ} 29^{\prime} 28^{\prime \prime}$ & E $120^{\circ} 43^{\prime} 42^{\prime \prime}$ & TAIE \\
\hline Gastrodia leoui & Chaiyi, Taiwan & Gle & 2 & $\mathrm{~N} 23^{\circ} 29^{\prime} 28^{\prime \prime}$ & E $120^{\circ} 43^{\prime} 42^{\prime \prime}$ & TAIE \\
\hline Gastrodia nantoensis & Nantou, Taiwan & Gna & 2 & $\mathrm{~N} 23^{\circ} 41^{\prime} 17^{\prime \prime}$ & E $120^{\circ} 47^{\prime} 27^{\prime \prime}$ & TAIE \\
\hline Gastrodia nipponica & Taipei, Taiwan & Gni & 2 & $\mathrm{~N} 24^{\circ} 51^{\prime} 05^{\prime \prime}$ & E $121^{\circ} 32^{\prime} 11^{\prime \prime}$ & TAIE \\
\hline Gastrodia pubilabiata & Nantou, Taiwan & Gpu & 2 & $\mathrm{~N} 23^{\circ} 40^{\prime} 23^{\prime \prime}$ & E $120^{\circ} 47^{\prime} 54^{\prime \prime}$ & TAIE \\
\hline Gastrodia shimizuana & Pingtung, Taiwan & Gsh & 2 & $\mathrm{~N} 22^{\circ} 12^{\prime} 12^{\prime \prime}$ & E $120^{\circ} 47^{\prime} 16^{\prime \prime}$ & TAIE \\
\hline Gastrodia theana & Nantou, Taiwan & Gth & 2 & N $23^{\circ} 51^{\prime} 57^{\prime \prime}$ & E $120^{\circ} 55^{\prime} 42^{\prime \prime}$ & TAIE \\
\hline Gastrodia uraiensis & Taipei, Taiwan & Gur & 2 & $\mathrm{~N} 24^{\circ} 50^{\prime} 41^{\prime \prime}$ & E $121^{\circ} 33^{\prime} 34^{\prime \prime}$ & TAIE \\
\hline
\end{tabular}

Note: TAIE $=$ the herbarium of the Taiwan Endemic Species Research Institute.

Sample size, location, coordinates, and voucher specimens are indicated. 
extracted from silica-dried plant materials using the Plant Genomic DNA Extraction Kit (RBC Bioscience, Taipei, Taiwan).

\section{Isolation of microsatellite DNA loci and identification}

In order to develop the molecular markers for evaluating the genetic variation of populations and testing transferability in Gastrodia species, we selected one individual of G. flabilabella to build (AG)n, (AC)n, (TTG)n, (TCC)n, (ACG), (CCA)n, (AACT)n, and (AGAT)n enrich DNA library. Microsatellite loci were isolated following the magnetic bead enrichment method (Liao et al. 2009; Hsu et al. 2013), modified from the method proposed by Zane et al. (2002) based on AFLP, magnetic bead enrichment, and TA cloning protocol. Genomic DNA of G. flabilabella was digested using the restriction enzyme MseI (Promega, Madison, Wisconsin, USA) and DNA fragments from 400 to 1000 bps were isolated from agarose gels using the HiYield ${ }^{\text {TM }}$ Gel PCR DNA Fragments Extraction Kit (RBC Bioscience). The purified partial genomic library was ligated to adaptors (complementary oligo A: 5' -TACTCAGGACTCAT-3' and 5' phosphorylated oligo B: 5'-GACGATGAGTCCTGAG$\left.3^{\prime}\right)$. The partial genomic library was enriched using $15 \mathrm{cy}-$ cles of prehybridization polymerase chain reaction (PCR) using adaptor specific primers (5'-GATGAGTCCTGAGTAAN-3', hereafter referred to as MseI-N). The enriched partial genomic library was denatured and hybridized to eight different biotinylated probes [Biotin-(AG) ${ }_{15}$, Biotin$(\mathrm{AC})_{15}$, Biotin-(TTG) $)_{10}$, Biotin- $(\mathrm{TCC})_{10}$, Biotin- $(\mathrm{ACG})_{10}$, Biotin- $(\mathrm{CCA})_{10}$, Biotin- $(\mathrm{AACT})_{8}$, and Biotin-(AGAT) $)_{8}$ at $68^{\circ} \mathrm{C}$ for 1 hour for enrichment. The DNA fragments hybridized to probes was incubated and captured using Streptavidin MagneSphere Paramagnetic Particles (Promega) at $42^{\circ} \mathrm{C}$ for 2 hours. The microsatellite enriched DNA fragments were eluted with high- and low-salt solutions and used as template DNAs for 25 cycles of PCR amplification. The microsatellite enriched DNA fragments were then used as templates for 25 cycles of PCR amplification using MseI-N. The PCR products were purified using the HiYield $^{\mathrm{TM}}$ Gel PCR DNA Fragments Extraction Kit (RBC Bioscience) and then cloned directly into the $p \mathrm{GEM}^{\ominus}-\mathrm{T}$ Easy Vector System (Promega). Plasmids containing the PCR product were isolated using an alkaline lysis protocol (Birnboim and Doly 1979), screened using PCR with primer pairs: $(\mathrm{AG})_{10}$ or $(\mathrm{AC})_{10} / \mathrm{SP} 6$ or T7), and purified with a PureYield $^{\mathrm{TM}}$ Plasmid Miniprep System (Promega). The selected plasmids were subsequently sequenced in both directions using an ABI BigDye3.1 Terminator Cycle Sequencing Kit (Applied Biosystems, USA) with the ABI $\mathrm{PRISM}^{\odot} 3700$ DNA Automated Sequencer. Sequences enclosing tandem repeat sequences were recognized using Tandem Repeats Finder version 4.07b (Benson 1999) by general setting on 2, 3, and 5 of match, mismatch, and indel for alignment parameters and 20 for minimum alignment score to report repeat. The pair of specific primers for each microsatellite locus detected by Tandem Repeats Finder was designed using FastPCR software version 6.4.18 (Kalendar et al. 2011) based on the setting of parameters at a PCR product size ranging from 100 to $400 \mathrm{bp}$, an optimum annealing temperature of $55^{\circ} \mathrm{C}$, and a GC content ranging from $35 \%$ to $70 \%$.

\section{DNA amplification and genotyping}

To optimize PCR at various annealing temperatures, we evaluated each primer pair using a gradient PCR procedure. All primer pairs were tested for PCR amplification on DNA extracted from each species, i.e., two individuals of each 17 taxa. The protocol was executed at $94^{\circ} \mathrm{C}$ for $5 \mathrm{~min}$, followed by 30 cycles of $94^{\circ} \mathrm{C}$ for $30 \mathrm{~s}, 48-65^{\circ} \mathrm{C}$ for $30 \mathrm{~s}, 72^{\circ} \mathrm{C}$ for $30 \mathrm{~s}$, and a final extension of $72^{\circ} \mathrm{C}$ for 10 minutes with the LabnetMultiGene 96-well Gradient Thermal Cycler (Labnet, Edison, NJ, USA). PCR products were checked by $10 \%$ PAGE electrophoresis to separate the target DNA bands and which were following confirmed based on cloning and sequencing. These SSR primer pairs with confirmed target DNA bands were chosen for polymorphism evaluation.

To investigate genetic polymorphisms, 20 individuals from each of four taxa were selected (Table 1). PCR reaction cocktail contained $20 \mathrm{ng}$ template DNA, $0.2 \mu \mathrm{M}$ each of forward and reverse primers, $2 \mu \mathrm{L} 10 \times \mathrm{PCR}$ reaction buffer, $2 \mathrm{mM}$ dNTP mix, $2 \mathrm{mM} \mathrm{MgCl}$, $0.5 \mathrm{U}$ Taq DNA polymerase (Promega), plus adding sterile water to total volume to $20 \mu \mathrm{L}$. PCR amplifications were executed by a Labnet MultiGene 96-well Gradient Thermal Cycler (Labnet). The PCR protocol was piloted at $94^{\circ} \mathrm{C}$ for $5 \mathrm{~min}$, followed by 30 cycles of $94^{\circ} \mathrm{C}$ for $30 \mathrm{~s}$, at the optimal annealing temperature $(\mathrm{Ta})$ for $30 \mathrm{~s}, 72^{\circ} \mathrm{C}$ for $30 \mathrm{~s}$, and a final extension of $72^{\circ} \mathrm{C}$ for 10 minutes (Chiang et al. 2012). PCR products were separated by electrophoresis on a $10 \%$ polyacrylamide gel (acrylamide: bisacrylamide 29: 1, $80 \mathrm{~V}$ for 14-16 hours) and determined the allele size by a 25 or 50 bp DNA Step Ladder (Promega). The bands of amplicons were then imaged under UV light using the Flo Gel FGIS-3 fluorescent gel image system (Top BIO Co., Taipei, Taiwan), and the sizes of bands were estimated using Quantity One software version 4.62 (Bio-Rad Laboratories, Hercules, California, USA).

\section{Genetic variation analysis}

Several genetic variation parameters were calculated using GenAlEx version 6.5 (Peakall and Smouse 2012), including the number of alleles $(\mathrm{Na})$, the number of effective alleles $(\mathrm{Ne}$ ), the observed and expected heterozygosity ( $\mathrm{Ho}$ and $H e)$, Shannon's information index $(H)$, fixation index $\left(F_{I S}\right)$. 
Hardy-Weinberg equilibrium $\left(H_{W E}\right)$ was evaluated using Arlequin software version 3.5.1.2 (Excoffier and Lischer 2010).

\section{Results and discussion}

Enrichment microsatellite library and sequencing results

We sequenced 1047 positive plasmids from eight microsatellite enrich libraries and confirmed 257 microsatellite loci from SSR enrich library (Table 2). Among the derived repeats of microsatellite loci, the di-, tri-, tetra-, penta-, and hexanucleotide motif was existed in 106 (41.25\%), 120 (46.69\%), 9 (3.05\%), 11 (4.28\%) and 9 (1.67\%) loci, respectively (Table 2). Di- (41.25\%) and trinucleotide repeats $(46.69 \%)$ comprised the largest group of repeat motifs and accounted for more than four-fifths of the total SSR content, while the rest amounted to less than $12.06 \%$. Generally, di- and trinucleotide repeats overstepped other types of repeats in all the species and mostly contributed to the major fraction of SSRs (Wei et al. 2014). Among the repeat motifs within G. flavilabella, di- and trinucleotide repeats were the commonest motifs, representing for $87.94 \%$, similar to Sesamum indicum (Wei et al. 2014), Arabidopsis thaliana, Sorghum bicolor (Sonah et al. 2011), and Brassica napus (Cheng et al. 2009).

\section{Development of microsatellite markers}

Totally, we designed 144 microsatellite primer pairs based on the flanking sequences from 257 microsatellite loci. All primer pairs were screened using a gradient PCR protocol with a Labnet MultiGene ${ }^{\mathrm{Tm}}$ 96-well Gradient Thermal Cycler (Labnet) to find the best annealing temperature. Finally, 28 primer pairs showed desired DNA bands and

\begin{tabular}{|c|c|c|c|c|c|c|c|}
\hline No. of repeat units & Di- & Tri- & Tetra- & Penta- & Hexa- & Mix & Total \\
\hline 4 & 1 & 13 & 8 & 1 & 0 & 0 & 23 \\
\hline 5 & 0 & 5 & 0 & 1 & 0 & 0 & 6 \\
\hline 6 & 2 & 4 & 0 & 0 & 1 & 0 & 7 \\
\hline 7 & 5 & 4 & 0 & 0 & 0 & 0 & 9 \\
\hline 8 & 4 & 3 & 0 & 0 & 0 & 0 & 7 \\
\hline 9 & 3 & 4 & 0 & 0 & 0 & 0 & 7 \\
\hline 10 & 6 & 4 & 0 & 0 & 2 & 0 & 12 \\
\hline 11 & 2 & 4 & 0 & 0 & 0 & 0 & 6 \\
\hline 12 & 3 & 3 & 0 & 0 & 2 & 0 & 8 \\
\hline$\geq 13$ & 80 & 76 & 1 & 9 & 4 & 2 & 172 \\
\hline Total & 106 & 120 & 9 & 11 & 9 & 2 & 257 \\
\hline
\end{tabular}

were selected for future diversity evaluation. The characteristics of 28 microsatellite loci are listed in Table 3. Of the 28 loci, 26 are complete microsatellite loci, including 13 carrying a dinucleotide motif, 11 with a trinucleotide motif, 1 with a pentanucleotide motif, and 1 with a hexanucleotide motif, and 2 remaining loci are carried a compound motif. The sequences of 28 loci reported in this paper are available from GenBank (accession numbers: LK934509-LK934536) (Table 3).

\section{Genotyping and population genetics analysis}

To inspect the level of genetic polymorphism at each locus, 20 individuals were collected in the field from the remaining wild population of G. flabilabella (Table 1). All the 28 new microsatellite loci identified in G. flabilabella were successfully amplified. Of the 28 loci, 12 microsatellite loci were monomorphic and 16 were polymorphic (Table 4). Genetic variation indices for 16 polymorphic loci, including the number of alleles $(\mathrm{Na})$, the number of effective alleles $(\mathrm{Ne})$, the observed and expected heterozygosity ( $\mathrm{Ho}$ and $\mathrm{He}$ ), Shannon's information index $(H)$ and fixation index $\left(F_{I S}\right)$, were estimated. $\mathrm{Ne}$ represents here an estimate of the number of equally frequent alleles in a model population following the formula of $\mathrm{Ne}=1 /(\mathrm{H}-\mathrm{He})$. As shown in Table 4, $\mathrm{Na}$ ranged from 2 to $15, \mathrm{Ne}$ varied from 1.08 to 8.85 , $\mathrm{Ho}$ ranged from 0 to 1.00 and mean was 0.163 , and $H e$ varied from 0.08 to 0.89 and mean was 0.444 . The Shannon's information index $(H)$ and fixation index $\left(F_{I S}\right)$ ranged from 0.17 to 2.41 and from -1.00 to 1.00 , and the mean was 0.882 and 0.697 , respectively. Significant deviations from Hardy-Weinberg equilibrium $\left(H_{W E}\right)$ were detected at all loci (Table 4).

To test the transferability and genetic diversity, 20 individuals from each of three taxa, including G. elata, G. javanica, and G. confusoides, were tested. Of the 28 loci, 13, 7, and 17 markers worked in G. elata, G. javanica, and G. confusoides, respectively. Of the 13,7 , and 17 microsatellite loci, 9, 5, and 12 were monomorphic and 4, 2, and 5 were polymorphic (Table 4). In addition, three loci, including CT6-90, CT6-99, and CT-AG-157, are monomorphic within each of four species, but polymorphic between species. As shown in Table 4, the ranges for the $\mathrm{Na}, \mathrm{Ne}, \mathrm{Ho}$ and $\mathrm{He}$ were varied from 1 to $7,1.00$ to $4.37,0.00$ to 1.00 , and 0.33 to 0.77 in G. elata, 1 to $2,1.00$ to $2.00,0.11$ to 1.00 , and 0.10 to 0.50 in G. javanica, and 1 to $7,1.00$ to $4.35,0.00$ to 1.00 , and 0.06 to 0.77 in G. confusoides. The Shannon's information index $(H)$ and fixation index $\left(F_{I S}\right)$ ranged from 0.69 to 1.64 and from -1.00 to 1.00 , and the mean was 1.113 and 0.147 in G. elata, from 0.21 to 0.69 and from -1.00 to -0.056 , and the mean was 0.450 and 0.528 in G. javanica, and from 0.13 to 1.64 and from -1.00 to -0.056 , and the mean was 0.670 and -0.266 in $G$. 
Table 3 Summary of general information for the 28 microsatellite loci isolated from Gastrodia flavilabella

\begin{tabular}{|c|c|c|c|c|c|c|c|c|}
\hline \multirow[t]{2}{*}{ Locus } & \multirow[t]{2}{*}{ Repeat motif } & \multirow[t]{2}{*}{ Primer sequence $\left(5^{\prime}-3^{\prime}\right)$} & \multirow[t]{2}{*}{ Allele size (bps) } & \multicolumn{4}{|c|}{$\mathrm{Ta}\left({ }^{\circ} \mathrm{C}\right)$} & \multirow{2}{*}{$\begin{array}{l}\text { Genbank } \\
\text { accession no }\end{array}$} \\
\hline & & & & Gfl & Gel & Gja & Gco & \\
\hline \multirow[t]{2}{*}{ CT3-32 } & $(\mathrm{GGA})_{9}$ & F: TAACGGGGAATGGGGAGGCG & $137-146$ & 52 & - & 54 & - & LK934509 \\
\hline & & R: TTGCGATCCCTCCCCTGTAC & & & & & & \\
\hline \multirow[t]{2}{*}{ CT6-4 } & $(G A)_{29}$ & F: CAAGAATAGGTGCCAACCTC & $110-151$ & 55 & - & - & - & LK934510 \\
\hline & & R: GTGAGTTACTAGCGTGCGGC & & & & & & \\
\hline \multirow[t]{2}{*}{ CT6-35 } & $(\mathrm{TG})_{84}$ & F: GTCTGTTCCATTTGATATTG & $250-252$ & 55 & - & - & 50 & LK934511 \\
\hline & & R: GCAGTAATGACCTTTGTAGT & & & & & & \\
\hline \multirow[t]{2}{*}{ CT6-65 } & $(\mathrm{TGT})_{36}$ & F: CACCGAGCTIITTGTCAATG & $247-262$ & 55 & 52 & - & 51 & LK934512 \\
\hline & & R: GCAATAACAATAGTAGCAGC & & & & & & \\
\hline \multirow[t]{2}{*}{ CT6-90 } & $(T \mathrm{TG})_{7}$ & F: CAACCAAGACAAGACTCATG & 132 & 55 & 55 & 52 & 55 & LK934513 \\
\hline & & R: ACATTCTTCCCTGGATGTTC & & & & & & \\
\hline \multirow[t]{2}{*}{ CT6-99 } & $(C A A)_{7}$ & F: GGCATTATCCTGTTATACTC & 138 & 55 & 50 & - & 55 & LK934514 \\
\hline & & R: GGGCTITCATTTGATCATGC & & & & & & \\
\hline \multirow[t]{2}{*}{ CT6-120 } & $(\mathrm{CACAG})_{38}$ & F: TAGCAGCCATAAGTAAAGCC & 316 & 55 & - & - & - & LK934515 \\
\hline & & R: GTCGAGGATCAAATGAATTG & & & & & & \\
\hline \multirow[t]{2}{*}{ CT6-142 } & $(\mathrm{AAC})_{7}$ & F: GTCATGCACATTCTTCCCTG & $128-131$ & 55 & 55 & - & 55 & LK934516 \\
\hline & & R: AGACTCATGTTGTTGATCCC & & & & & & \\
\hline \multirow[t]{2}{*}{ CT-ACT-74 } & $(A G)_{29}$ & F: GAGGTCCAATCTAAGATTTC & $122-156$ & 54 & - & - & - & LK934517 \\
\hline & & R: CATGATATAATTCTCACCCC & & & & & & \\
\hline \multirow[t]{2}{*}{ CT-ACT-88 } & $(\mathrm{TGA})_{9}$ & F: TAGTGGATTTGGAGTTTGAG & 101 & 54 & - & - & 51 & LK934518 \\
\hline & & R: CTCATCTITGATACCTCTTC & & & & & & \\
\hline \multirow[t]{2}{*}{ CT-ACT-136 } & $(\mathrm{CT})_{12}$ & F: ATTTAGGGTCATCGAGCACC & $140-142$ & 54 & 55 & 55 & 54 & LK934519 \\
\hline & & R: TCGGCAAGGTGTCAAGACTC & & & & & & \\
\hline \multirow[t]{2}{*}{ CT-AG-35 } & $(G A)_{12}$ & F: TCTTCCCGCACCTCTTCAAC & $133-137$ & 52 & 55 & 55 & 55 & LK934520 \\
\hline & & R: TTCAGAAGCATGGCACTGGG & & & & & & \\
\hline \multirow[t]{2}{*}{ CT-AG-45 } & $(\mathrm{CTT})_{12}$ & F: CAGAAGCCAACATATCCATC & $115-121$ & 50 & 54 & - & 52 & LK934521 \\
\hline & & R: TCTGAAATTTAGTGTAGCGG & & & & & & \\
\hline \multirow[t]{2}{*}{ CT-AG-55 } & $(\mathrm{TGCCTC})_{5}$ & F: GTGGGGAGATTACTATTACG & $108-110$ & 50 & 50 & - & 55 & LK934522 \\
\hline & & R: AAGGAAAGGCGTAAGGATAG & & & & & & \\
\hline \multirow[t]{2}{*}{ CT-AG-85 } & $(\mathrm{TG})_{9}(\mathrm{AG})_{28}$ & F: CCCATATGTCCTTGGTCATC & $208-248$ & 54 & - & - & - & LK934523 \\
\hline & & R: GCTTACAACTTTCTCCCTTC & & & & & & \\
\hline \multirow[t]{2}{*}{ CT-AG-88 } & $(A G)_{15}$ & F: ACAACCTACACTGTCTAAAG & 152 & 55 & 54 & - & 55 & LK934524 \\
\hline & & R: CTIIIITGTGTGGTCACCG & & & & & & \\
\hline \multirow[t]{2}{*}{ CT-AG-114 } & $(\mathrm{TG})_{13}$ & F: AGTGATATGATAACACCCTC & 104 & 50 & - & - & - & LK934525 \\
\hline & & R: TAGATCTCTAGCTTCAACTC & & & & & & \\
\hline CT-AG-127 & $(\mathrm{TC})_{9}$ & F: AAGCTTCGCTGCCCTCTTCG & $117-123$ & 54 & - & - & - & LK934526 \\
\hline & & R: TTGGTTCGGGCCAGAGCTG & & & & & & \\
\hline CT-AG-140 & $(A G)_{15}$ & F: AGTCCTGCCTTCAAGCCTTG & $120-126$ & 54 & 55 & 55 & 55 & LK934527 \\
\hline & & R: GAAGGATTCAAGCATGGGAG & & & & & & \\
\hline CT-AG-144 & $(A G)_{18}$ & F: GGCGATGTCAATTCAACAAG & $113-115$ & 52 & 55 & 55 & 55 & LK934528 \\
\hline & & R: TAACGATAGCTGCCTTCCAC & & & & & & \\
\hline CT-AG-145 & $(\mathrm{TC})_{14}(\mathrm{ACTC})_{3}$ & F: ATCTTCGTACATCTAACCCG & 140 & 54 & - & - & 55 & LK934529 \\
\hline & & R: AATGAGCTCGTTGCAGCTTC & & & & & & \\
\hline
\end{tabular}


Table 3 Summary of general information for the $\mathbf{2 8}$ microsatellite loci isolated from Gastrodia flavilabella (Continued)

\begin{tabular}{|c|c|c|c|c|c|c|c|c|}
\hline \multirow[t]{2}{*}{ CT-AG-157 } & $(\mathrm{TG})_{14}$ & F: TGCAGTAATAGCATTTGCAG & 120 & 56 & 55 & - & 55 & LK934530 \\
\hline & & R: AGGCTGCCACTGTACTIITC & & & & & & \\
\hline \multirow{2}{*}{ CT-AGAT-19 } & $(\mathrm{TC})_{19}$ & F: TACATTGATTAGGATGCCTC & 169 & 55 & 50 & - & 50 & LK934531 \\
\hline & & R: ACATTTGTGCCTCCTCCAAC & & & & & & \\
\hline \multirow[t]{2}{*}{ CT-AGAT-26 } & $(\mathrm{TG})_{88}$ & F: GAATGATGCTATGTGTGCTG & 295 & 55 & - & - & - & LK934532 \\
\hline & & R: TGCAGTAATAGCATTTGCAG & & & & & & \\
\hline \multirow[t]{2}{*}{ CT-AGAT-131 } & $(C C A)_{7}$ & F: TTCAATCGCTAGTAGCTCTG & 139 & 55 & - & - & 50 & LK934533 \\
\hline & & R: GTTGACATTTAGTGGAGAGG & & & & & & \\
\hline \multirow[t]{2}{*}{ CT-CCA-71 } & $(\mathrm{TGG})_{14}$ & F: ACATGAGTAGGAGCATCCTC & $150-156$ & 50 & - & - & 50 & LK934534 \\
\hline & & R: TTCTCTTCCCCACAGCTGC & & & & & & \\
\hline \multirow[t]{2}{*}{ CT-CCA-108 } & $(C C A)_{127}$ & F: CATGGTGGGACATAAAACTG & $489-516$ & 47 & - & - & - & LK934535 \\
\hline & & R: GTGGTTGTAGTCATCACTCC & & & & & & \\
\hline \multirow[t]{2}{*}{ CT-CCA-137 } & $(C C A)_{6}$ & F: AATCTCAGAGCCTTTCCCAG & 150 & 55 & - & - & 55 & LK934536 \\
\hline & & R: TTGGAGGTTGCTTGTAGAGC & & & & & & \\
\hline
\end{tabular}

Note: $\mathrm{F}=$ the forward primer; $\mathrm{R}=$ the reverse primer; $\mathrm{Ta}=$ optimized annealing temperature.

javanica. Significant deviations from Hardy-Weinberg equilibrium $\left(H_{W E}\right)$ were detected at 4 of 4,1 of 2 , and 4 of 5 polymorphic loci (Table 4).

For orchids, only few researches were used simple sequence repeats to evaluate the genetic diversity. The genetic diversity, including the means of the observed $(\mathrm{Ho})$ and expected heterozygosity $(\mathrm{He})$ (Table 4), of G. flabilabella was low compared with that of other Orchidaceae species, such as Dendrobium huoshanense (0.512 and 0.569) (Wang et al. 2012b), Dendrobium officinale (0.720 and 0.740) (Xie et al. 2010), Dendrobium officinale (0.514 for $\mathrm{Ho}$ ) (Lu et al. 2012), and Dendrobium nobile (0.350 and 0.608) (Lu et al. 2014). Unfortunately, no data for any Gastrodia taxa or mycoheterotrophic orchids are available for the comparison of genetic variability. However, the low observed and expected heterozygosity values implied that rare and mycoheterotrophic taxa tend to possess low levels of genetic diversity due to stochastic losses of genetic polymorphisms resulting from genetic drift (cf. Ge et al. 2014). In addition, significant deviations from Hardy-Weinberg equilibrium $\left(H_{W E}\right)$ were detected at all loci in the remained population, and these deviations were credited to the heterozygote deficiency likely due to the unique interactions between orchids and pollinators (Boberg et al. 2014). Besides, the habitat preferences (Mallet et al. 2014) strengthened the isolation among populations.

\section{Test the transferability}

To test the transferability of these microsatellite loci, we tested the primers in 13 other Gastrodia taxa (Table 1).
Two individuals of each taxon were used in the evaluation of cross-amplification. Of the 28 loci, 11 to 17 loci were transferable to each of the 13 taxa of Gastrodia (Table 5), and the annealing temperatures are listed on Table 3. Three loci, including CT-ACT-136, CT-AG-88, and CTAG-144, were transferable, and four loci, including CT6-4, CT6-35, CT-AG-85, and CT-AG-114, did not work in all taxa (Table 5). In addition, 13 of 28 loci successfully amplifying more than 10 taxa will be useful across species. Nonetheless, population genetics, phylogeographic patterns, and process of speciation among the Gastrodia taxa remain unclear. The primer set of these 13 microsatellite markers with high transferability represents a useful tool of genetic markers for interspecific researches.

\section{Conclusions}

For conservation purposes, 28 new microsatellite loci, including 12 monomorphic and 16 polymorphic loci, were isolated from G. flabilabella. The genetic diversity indices assessed using these 16 polymorphic microsatellite loci for the remained populations of this endemic and vulnerable species revealed that these markers are potentially useful for future studies, especially those focusing on evaluating the genetic variation and identifying distinct evolutionary units within populations for conservation management. Genetic diversity was characterized for three other related species using these 28 microsatellite markers. Furthermore, successful amplification in 13 other Gastrodia taxa indicated the transferability of these primer pairs. The interspecies transferability made these microsatellite loci useful for 
Table 4 Genetic diversity characteristics of the 28 microsatellite loci tested on four Gastrodia taxa

\begin{tabular}{|c|c|c|c|c|c|c|c|c|c|c|c|c|c|c|c|c|c|c|c|c|c|c|c|c|}
\hline \multirow[b]{2}{*}{ Locus } & \multicolumn{6}{|c|}{ Gastrodia flavilabella } & \multicolumn{6}{|c|}{ Gastrodia elata } & \multicolumn{6}{|c|}{ Gastrodia javanica } & \multicolumn{6}{|c|}{ Gastrodia confusoides } \\
\hline & $\mathrm{Na}$ & $\mathrm{Ne}$ & Ho & $\mathrm{He}$ & $H$ & $F_{I S}$ & $\mathrm{Na}$ & $\mathrm{Ne}$ & Ho & $\mathrm{He}$ & $H$ & $F_{I S}$ & $\mathrm{Na}$ & $\mathrm{Ne}$ & Ho & $\mathrm{He}$ & $H$ & $F_{I S}$ & $\mathrm{Na}$ & $\mathrm{Ne}$ & Ho & $\mathrm{He}$ & $H$ & $F_{I S}$ \\
\hline CT3-32 & 4 & 1.23 & 0.00 & $0.19^{*}$ & 0.43 & 1.000 & - & - & - & - & - & - & 1 & 1.00 & - & - & - & - & - & - & - & - & - & - \\
\hline CT6-4 & 15 & 8.85 & 0.10 & $0.89^{*}$ & 2.41 & 0.887 & - & - & - & - & - & - & - & - & - & - & - & - & - & - & - & - & - & - \\
\hline CT6-35 & 2 & 1.08 & 0.00 & $0.08^{*}$ & 0.17 & 1.000 & - & - & - & - & - & - & - & - & - & - & - & - & - & - & - & - & - & - \\
\hline CT6- 65 & 5 & 2.94 & 0.32 & $0.66^{*}$ & 1.23 & 0.515 & 1 & 1.00 & - & - & - & - & - & - & - & - & - & - & 2 & 1.06 & 0.06 & 0.06 & 0.13 & -0.030 \\
\hline CT6-90 & 1 & 1.00 & - & - & - & - & 1 & 1.00 & - & - & - & - & 1 & 1.00 & - & - & - & - & 1 & 1.00 & - & - & - & - \\
\hline CT6-99 & 1 & 1.00 & - & - & - & - & 1 & 1.00 & - & - & - & - & - & - & - & - & - & - & 1 & 1.00 & - & - & - & - \\
\hline CT6-120 & 1 & 1.00 & - & - & - & - & - & - & - & - & - & - & - & - & - & - & - & - & - & - & - & - & - & - \\
\hline CT6-142 & 2 & 1.04 & 0.00 & $0.04^{*}$ & 0.10 & 1.000 & 1 & 1.00 & - & - & - & - & - & - & - & - & - & - & 1 & 1.00 & - & - & - & - \\
\hline CT-ACT-74 & 10 & 4.03 & 0.16 & $0.75^{*}$ & 1.80 & 0.783 & - & - & - & - & - & - & - & - & - & - & - & - & - & - & - & - & - & - \\
\hline CT-ACT-88 & 1 & 1.00 & - & - & - & - & - & - & - & - & - & - & - & - & - & - & - & - & - & - & - & - & - & - \\
\hline CT-ACT-136 & 2 & 2.00 & 1.00 & $0.50^{*}$ & 0.69 & -1.000 & 1 & 1.00 & - & - & - & - & 2 & 2.00 & 1.00 & $0.50^{*}$ & 0.69 & -1.000 & 1 & 1.00 & - & - & - & - \\
\hline CT-AG-35 & 3 & 2.56 & 0.00 & $0.61^{*}$ & 1.00 & 1.000 & 7 & 4.37 & 0.05 & $0.77^{*}$ & 1.64 & 0.935 & 2 & 1.11 & 0.11 & 0.10 & 0.21 & -0.056 & 2 & 1.11 & 0.00 & $0.10^{*}$ & 0.20 & 1.000 \\
\hline CT-AG-45 & 3 & 1.09 & 0.00 & $0.08^{*}$ & 0.20 & 1.000 & 1 & 1.00 & - & - & - & - & - & - & - & - & - & - & 1 & 1.00 & - & - & - & - \\
\hline CT-AG-55 & 2 & 1.95 & 0.00 & $0.49^{*}$ & 0.68 & 1.000 & 1 & 1.00 & - & - & - & - & - & - & - & - & - & - & 2 & 2.00 & 1.00 & $0.50^{*}$ & 0.69 & -1.000 \\
\hline CT-AG-85 & 8 & 3.97 & 0.02 & $0.75^{*}$ & 1.62 & 0.972 & 5 & 3.86 & 1.00 & $0.74^{*}$ & 1.43 & -0.349 & - & - & - & - & - & - & - & - & - & - & - & - \\
\hline CT-AG-88 & 1 & 1.00 & - & - & - & - & - & - & - & - & - & - & - & - & - & - & - & - & 7 & 4.35 & 1.00 & $0.77^{*}$ & 1.64 & -0.299 \\
\hline CT-AG-114 & 1 & 1.00 & - & - & - & - & - & - & - & - & - & - & - & - & - & - & - & - & - & - & - & - & - & - \\
\hline CT-AG-127 & 3 & 1.14 & 0.00 & $0.12^{*}$ & 0.28 & 1.000 & - & - & - & - & - & - & - & - & - & - & - & - & - & - & - & - & - & - \\
\hline CT-AG-140 & 4 & 2.34 & 0.00 & $0.57^{*}$ & 0.97 & 1.000 & 4 & 1.49 & 0.00 & $0.33^{*}$ & 0.69 & 1.000 & 1 & 1.00 & - & - & - & - & 1 & 1.00 & - & - & - & - \\
\hline CT-AG-144 & 2 & 1.17 & 0.00 & $0.15^{*}$ & 0.28 & 1.000 & 1 & 1.00 & - & - & - & - & 1 & 1.00 & - & - & - & - & 1 & 1.00 & - & - & - & - \\
\hline CT-AG-145 & 1 & 1.00 & - & - & - & - & - & - & - & - & - & - & - & - & - & - & - & - & 1 & 1.00 & - & - & - & - \\
\hline CT-AG-157 & 1 & 1.00 & - & - & - & - & 1 & 1.00 & - & - & - & - & 1 & 1.00 & - & - & - & - & 1 & 1.00 & - & - & - & - \\
\hline CT-AGAT-19 & 1 & 1.00 & - & - & - & - & 2 & 2.00 & 1.00 & $0.50^{*}$ & 0.69 & -1.000 & - & - & - & - & - & - & 2 & 2.00 & 1.00 & $0.50^{*}$ & 0.69 & -1.000 \\
\hline CT-AGAT-26 & 1 & 1.00 & - & - & - & - & - & - & - & - & - & - & - & - & - & - & - & - & - & - & - & - & - & - \\
\hline CT-AGAT-131 & 1 & 1.00 & - & - & - & - & - & - & - & - & - & - & - & - & - & - & - & - & 1 & 1.00 & - & - & - & - \\
\hline CT-CCA-71 & 2 & 2.00 & 1.00 & $0.50^{*}$ & 0.69 & -1.000 & - & - & - & - & - & - & - & - & - & - & - & - & 1 & 1.00 & - & - & - & - \\
\hline CT-CCA-108 & 7 & 3.71 & 0.00 & $0.73^{*}$ & 1.57 & 1.000 & - & - & - & - & - & - & - & - & - & - & - & - & - & - & - & - & - & - \\
\hline CT-CCA-137 & 1 & 1.00 & - & - & - & - & - & - & - & - & - & - & - & - & - & - & - & - & 1 & 1.00 & - & - & - & - \\
\hline
\end{tabular}

$\begin{array}{lllllllllllllllllllllllllll}\text { Mean } & 3.071 & 1.896 & 0.163 & 0.444 & 0.882 & 0.697 & 2.077 & 1.480 & 0.513 & 0.585 & 1.113 & 0.147 & 1.286 & 1.159 & 0.555 & 0.300 & 0.450 & -0.528 & 1.588 & 1.324 & 0.612 & 0.386 & 0.67 & -0.266\end{array}$ The number of different alleles $(\mathrm{Na})$, number of effective alleles $(\mathrm{Ne})$, observed heterozygosity $\left(H_{0}\right)$, expected heterozygosity $(H e)$, Shannon's information index $(H)$, and fixation index $\left(F_{I S}\right)$ are reported. *Significant deviation from Hardy-Weinberg equilibrium: $\mathrm{P}<0.05$. 
Table 5 Result of cross-species transferability in 13 Gastrodia taxa using the $\mathbf{2 8}$ microsatellite primers developed from Gastrodia flavilabella

\begin{tabular}{|c|c|c|c|c|c|c|c|c|c|c|c|c|c|c|}
\hline Locus & $\begin{array}{l}\text { Gal } \\
(\mathrm{N}=2)\end{array}$ & $\begin{array}{l}\text { Gap } \\
(\mathrm{N}=2)\end{array}$ & $\begin{array}{l}\text { Gau } \\
(\mathrm{N}=2)\end{array}$ & $\begin{array}{l}\mathrm{Gcl} \\
(\mathrm{N}=2)\end{array}$ & $\begin{array}{l}\text { Gfo } \\
(N=2)\end{array}$ & $\begin{array}{l}\text { Ggr } \\
(N=2)\end{array}$ & $\begin{array}{l}\text { Gle } \\
(\mathrm{N}=2)\end{array}$ & $\begin{array}{l}\text { Gna } \\
(\mathrm{N}=2)\end{array}$ & $\begin{array}{l}\text { Gni } \\
(\mathrm{N}=2)\end{array}$ & $\begin{array}{l}\text { Gpu } \\
(\mathrm{N}=2)\end{array}$ & $\begin{array}{l}\text { Gsh } \\
(N=2)\end{array}$ & $\begin{array}{l}\text { Gth } \\
(\mathrm{N}=2)\end{array}$ & $\begin{array}{l}\text { Gur } \\
(\mathrm{N}=2)\end{array}$ & $\begin{array}{l}\text { Total } \\
\text { Species }\end{array}$ \\
\hline CT3-32 & - & - & - & - & - & - & - & - & 1 & - & 1 & 1 & - & 3 \\
\hline CT6-4 & - & - & - & - & - & - & - & - & - & - & - & - & - & 0 \\
\hline CT6-35 & - & - & - & - & - & - & - & - & - & - & - & - & - & 0 \\
\hline CT6- 65 & 1 & 1 & 1 & 1 & - & 1 & - & 1 & 1 & 1 & 1 & 1 & - & 10 \\
\hline CT6-90 & - & 1 & 1 & 1 & 1 & - & 1 & 1 & 1 & 1 & - & 1 & 1 & 10 \\
\hline CT6-99 & - & 1 & 1 & 1 & 1 & 1 & 1 & 1 & 1 & 1 & 1 & 1 & 1 & 12 \\
\hline CT6-120 & - & - & - & - & - & - & - & - & 1 & - & - & - & - & 1 \\
\hline CT6-142 & 1 & 1 & 1 & 1 & 1 & 1 & - & 1 & 1 & 1 & 1 & 1 & 1 & 12 \\
\hline CT-ACT-74 & - & - & - & - & 1 & 1 & - & - & - & 1 & 1 & - & - & 4 \\
\hline CT-ACT-88 & 1 & - & 1 & - & - & 1 & - & - & - & - & 1 & 1 & - & 5 \\
\hline CT-ACT-136 & 1 & 1 & 1 & 1 & 1 & 1 & 1 & 1 & 1 & 1 & 1 & 1 & 1 & 13 \\
\hline CT-AG-35 & 1 & 1 & 1 & 1 & 1 & - & 2 & 1 & 1 & 1 & 1 & - & 1 & 11 \\
\hline CT-AG-45 & 1 & - & 1 & 1 & - & - & 1 & 1 & 1 & 1 & - & 1 & - & 8 \\
\hline CT-AG-55 & 1 & - & 1 & 1 & 1 & 1 & 1 & 1 & 1 & 1 & 1 & 1 & 1 & 12 \\
\hline CT-AG-85 & - & - & - & - & - & - & - & - & - & - & - & - & - & 0 \\
\hline CT-AG-88 & 1 & 1 & 1 & 2 & 1 & 1 & 1 & 1 & 1 & 1 & 1 & 1 & 1 & 13 \\
\hline CT-AG-114 & - & - & - & - & - & - & - & - & - & - & - & - & - & 0 \\
\hline CT-AG-127 & - & - & 1 & - & - & - & - & - & - & - & - & - & - & 1 \\
\hline CT-AG-140 & 1 & 1 & - & 1 & 1 & 1 & 1 & 1 & 1 & 1 & 1 & 1 & 1 & 12 \\
\hline CT-AG-144 & 1 & 1 & 1 & 1 & 1 & 1 & 1 & 1 & 1 & 1 & 1 & 1 & 1 & 13 \\
\hline CT-AG-145 & 1 & 1 & 1 & 1 & 1 & 1 & 1 & 1 & 1 & 1 & 1 & - & 1 & 12 \\
\hline CT-AG-157 & 1 & - & 1 & 1 & 1 & 1 & 1 & 1 & 1 & - & 1 & 1 & 1 & 11 \\
\hline CT-AGAT-19 & 1 & - & 1 & - & 1 & - & - & - & - & 1 & 1 & - & - & 5 \\
\hline CT-AGAT-26 & - & - & - & 1 & 1 & - & - & - & - & - & - & - & - & 2 \\
\hline CT-AGAT-131 & - & - & - & 1 & 1 & - & - & 1 & - & - & - & 1 & - & 4 \\
\hline CT-CCA-71 & - & - & 1 & 1 & - & - & - & - & 1 & - & 1 & - & - & 4 \\
\hline CT-CCA-108 & - & - & 1 & - & - & - & - & - & - & - & - & - & - & 1 \\
\hline CT-CCA-137 & 1 & 1 & - & 1 & 1 & - & 1 & 1 & 1 & 1 & 1 & 1 & - & 10 \\
\hline No. of loci & 14 & 11 & 17 & 17 & 16 & 12 & 12 & 15 & 17 & 15 & 17 & 15 & 11 & \\
\hline
\end{tabular}

For loci that were successfully amplified, the number of alleles is given.

future research aiming to reconstruct the phylogeographic patterns and the process of speciation among closely related species. Additionally, the transferable microsatellite loci will be potentially useful for future studies that focus on establishing the standard operating system of molecular identification for Gastrodia elata, a traditional Chinese medicine.

\footnotetext{
Abbreviations

Na: The number of alleles; Ne: The number of effective alleles; Ho: The observed heterozygosity; He: The expected heterozygosity; H: Shannon's information index; $F_{I S}$ : The fixation index; $H_{W E}$ : The Hardy-Weinberg equilibrium.
}

\section{Competing interests}

The authors declare that they have no competing interests.

\section{Authors' contributions}

T-WH, T-YC and Y-CC supervised the project. C-CT, S-KY, T-WH, and Y-CC collected plant sample in the field. C-CT, P-YW, C-CK, M-CH, and Y-CC mined the SSR primers. P-YW, M-CH, T-YC, and analyzed the data. T-WH, T-YC, and Y-CC wrote the manuscript. All authors read and approved the final manuscript.

\section{Acknowledgements}

We thank Dr. Xun Gong for their assistance in collecting the Gastrodia elata. This work was supported by grants from the National Science Council, Taiwan (NSC 100-2621-B-110-001-MY3 and NSC 101-2621-B-110-003) to Y.-C. Chiang.

\section{Author details}

${ }^{1}$ Crop Improvement Division, Kaohsiung District Agricultural Research and Extension Station, Pingtung 908, Taiwan. ${ }^{2}$ Department of Life Science, National Cheng Kung University, Tainan 701, Taiwan. ${ }^{3}$ Department of Nursing, Meiho University, Pingtung 912, Taiwan. ${ }^{4}$ Department of Biological Sciences, National Sun Yat-sen University, Kaohsiung 804, Taiwan. ${ }^{5}$ Taiwan Society of Plant Systematics, Kaohsiung 804, Taiwan. ${ }^{6}$ Endemic Species Research Institute, Nantou 552, Taiwan. 
Received: 21 July 2014 Accepted: 29 September 2014

Published online: 09 October 2014

\section{References}

Baek NI, Choi SY, Park JK, Cho SW, Ahn EM, Jeon SG, Lee BR, Bahn JH, Shon IH (1999) Isolation and identification of succinic semialdehyde dehydrogenase inhibitory compound from the rhizome of Gastrodia elata Blume. Arch Pharm Res 22:219-224

Benson G (1999) Tandem repeats finder: a program to analyze DNA sequences. Nucleic Acids Res 27:573-580

Birnboim HC, Doly J (1979) A rapid alkaline procedure for screening recombinant plasmid DNA. Nucleic Acids Res 7:1513-1523

Boberg E, Alexandersson R, Jonsson M, Maad J, Agren J, Nilsson LA (2014) Pollinator shifts and the evolution of spur length in the moth-pollinated orchid Platanthera bifolia. Ann Bot 113:267-275

Cha JY, Igarashi T (1995) Armillaria species associated with Gastrodia elata in Japan. Eur J Forest Pathol 25:319-326

Cheng X, Xu J, Xia S, Gu J, Yang Y, Fu J, Qian X, Zhang S, Wu J, Liu K (2009) Development and genetic mapping of microsatellite markers from genome survey sequences in Brassica napus. Theor Appl Genet 118:1121-1131

Chiang YC, Shih HC, Huang MC, Ju LP, Hung KH (2012) The Characterization of microsatellite loci from an endemic tree Litsea hypophaea (Lauraceae) in Taiwan. Am J Bot 99:e251-e254

Chung SW, Hsu TC (2006) Gastrodia shimizuana, a newly recorded of Gastrodia (Orchidaceae) in Taiwan. Taiwania 51:50-52

Excoffier L, Lischer HEL (2010) Arlequin suite ver 3.5: a new series of programs to perform population genetics analyses under Linux and Windows. Mol Ecol Resour 10:564-567

Ge XJ, Hsu TW, Hung KH, Lin CJ, Huang CC, Huang CC, Chiang YC, Chiang TY (2012) Inferring multiple refugia and phylogeographical patterns in Pinus massoniana based on nucleotide sequence variation and DNA fingerprinting. PLoS One 7:e43717

Ge XJ, Hung KH, Ko YZ, Hsu TW, Gong X, Chiang TY, Chiang YC (2014) Genetic divergence and biogeographical patterns in Amentotaxus argotaenia species complex., Plant Mol Biol Rep, doi:10.1007/s11105-014-0742-0

Ho CS, Shih HC, Liu HY, Chiu ST, Chen MH, Ju LP, Ko YZ, Shih YS, Chen CT, Hsu TW, Chiang YC (2014) Development and characterization of 16 polymorphic microsatellite markers from Taiwan cow-tail fir, Keteleeria davidiana var. formosana (Pinaceae) and cross-species amplification in other Keteleeria taxa. BMC Res Notes 7:255, doi:10.1186/1756-0500-7-255

Hsu TC (2008) Taxonomy of Gastrodia (Orchidaceae) in Taiwan. Master thesis. Institute of Ecology and Evolutionary Biology, College of Life Science, National Taiwan University, Taiwan

Hsu TC, Kuo CM (2010) Supplements to the orchid flora of Taiwan (IV): Four additions to the genus Gastrodia. Taiwania 55:243-248

Hsu TW, Shih HC, Kuo CC, Chiang TY, Chiang YC (2013) Characterization of 42 microsatellite markers from poison ivy, Toxicodendron radicans (Anacardiaceae). Int J Mol Sci 14:20414-20426

IUCN (2012) IUCN red list categories and criteria: version 3.1, 2nd edn., Gland, Switzerland and Cambridge, UK

Kalendar R, Lee D, Schulman AH (2011) Java web tools for PCR, in silico PCR, and oligonucleotide assembly and analysis. Genomics 98:137-144

Leou C (2000) Gastrodia. In: Editorial Committee of the Flora of Taiwan (ed) Flora of Taiwan, vol 5, 2nd edn. Editorial Committee of the Flora of Taiwan, Taipei, Taiwan, pp 890-896

Liao PC, Gong X, Shih HC, Chiang YC (2009) Isolation and characterization of eleven polymorphic microsatellite loci from an endemic species, Pipe polysyphonum (Piperaceae). Conserv Genet 10:1911-1914

Liao PC, Tsai CC, Chou CH, Chiang YC (2012) Introgression between cultivars and wild populations of Momordica charantia L. (Cucurbitaceae) in Taiwan. Int J Mol Sci 13:6469-6491

Lu JJ, Suo NN, Hu X, Wang S, Liu JJ, Wang HZ (2012) Development and characterization of 110 novel EST-SSR markers for Dendrobium officinale (Orchidaceae). Am J Bot 99:e415-e420

Lu JJ, Kang JY, Ye SR, Wang HZ (2014) Isolation and characterization of novel EST-SSRs in the showy dendrobium, Dendrobium nobile (Orchidaceae). Genet Mol Res 13:986-991

Mallet B, Martos F, Blambert L, Pailler T, Humeau L (2014) Evidence for isolation-by-habitat among populations of an epiphytic orchid species on a small oceanic island. PLoS One 9:e87469
Peakall R, Smouse PE (2012) GenAlEx 6.5: genetic analysis in Excel. Population genetic software for teaching and research-an update. Bioinformatics 28:2537-2539

Sonah H, Deshmukh RK, Sharma A, Singh VP, Gupta DK, Gacche RN, Rana JC, Singh NK, Sharma TR (2011) Genome-wide distribution and organization of microsatellites in plants: an insight into marker development in Brachypodium. PLoS One 6:e21298

Tsai CC, Chen YKH, Chen CH, Weng IS, Tsai CM, Lee SR, Lin YS, Chiang YC (2013) Cultivar identification and genetic relationship of mango (Mangifera indica) in Taiwan using 37 SSR markers. Sci Hortic 164:196-201

Wang JC, Chiou WL, Chang HM (2012a) A preliminary red list of Taiwanese vascular plants. Endemic Species Research Institute, Nantou, Taiwan

Wang H, Chen NF, Zheng JY, Wang WC, Pei YY, Zhu GP (2012b) Isolation and characterization of eleven polymorphic microsatellite loci for the valuable medicinal plant Dendrobium huoshanense and cross-species amplification. Int J Mol Sci 13:16779-16784

Wei X, Wang L, Zhang Y, Qi X, Wang X, Ding X, Zhang J, Zhang X (2014) Development of simple sequence repeat (SSR) markers of sesame (Sesamum indicum) from a genome survey. Molecules 19:5150-5162

Xie ML, Hou BW, Han L, Ma YH, Ding XY (2010) Development of microsatellites of Dendrobium officinale and its application in purity identification of germplasm. Yao Xue Xue Bao 45:667-672

Zane L, Bargelloni L, Patarnello T (2002) Strategies for microsatellite isolation: a review. Mol Ecol 11:1-16

\section{doi:10.1186/s40529-014-0072-4}

Cite this article as: Tsai et al:: Analysis of microsatellites in the vulnerable orchid Gastrodia flavilabella: the development of microsatellite markers, and cross-species amplification in Gastrodia. Botanical Studies 2014 55:72.

\section{Submit your manuscript to a SpringerOpen ${ }^{\circ}$ journal and benefit from:}

- Convenient online submission

- Rigorous peer review

- Immediate publication on acceptance

- Open access: articles freely available online

- High visibility within the field

- Retaining the copyright to your article

Submit your next manuscript at $>$ springeropen.com 